\title{
High levels of soluble VEGF receptor 1 early after trauma are associated with shock, sympathoadrenal activation, glycocalyx degradation and inflammation in severely injured patients: a prospective study
}

Sisse R Ostrowski ${ }^{*}$, Anne Marie Sørensen ${ }^{2,3}$, Nis A Windeløv ${ }^{1,2}$, Anders Perner ${ }^{4}$, Karen-Lise Welling ${ }^{5}$, Michael Wanscher ${ }^{6}$, Claus F Larsen ${ }^{3}$ and Pär I Johansson ${ }^{1}$

\begin{abstract}
Background: The level of soluble vascular endothelial growth factor receptor 1 (sVEGFR1) is increased in sepsis and strongly associated with disease severity and mortality. Endothelial activation and damage contribute to both sepsis and trauma pathology. Therefore, this study measured sVEGFR1 levels in trauma patients upon hospital admission hypothesizing that SVEGFR1 would increase with higher injury severity and predict a poor outcome.

Methods: Prospective observational study of 80 trauma patients admitted to a Level I Trauma Centre. Data on demography, biochemistry, Injury Severity Score (ISS), transfusions and 30-day mortality were recorded and plasma/ serum (sampled a median of 68 min (IQR 48-88) post-injury) was analyzed for sVEGFR1 and biomarkers reflecting sympathoadrenal activation (adrenaline, noradrenaline), tissue injury (histone-complexed DNA fragments, hcDNA), endothelial activation and damage (von Willebrand Factor Antigen, Angiopoietin-2, soluble endothelial protein C receptor, syndecan-1, soluble thrombomodulin (sTM)), coagulation activation/inhibition and fibrinolysis (prothrombinfragment $1+2$, protein $C$, activated Protein C, tissue-type plasminogen activator, plasminogen activator inhibitor-1, D-dimer) and inflammation (interleukin-6). Spearman correlations and regression analyses to identify variables associated with SVEGFR1 and its predictive value.

Results: Circulating SVEGFR1 correlated with injury severity (ISS, rho $=0.46$ ), shock $(S B E$, rho $=-0.38$; adrenaline, rho $=0.47$ ), tissue injury ( $h C D N A$, rho $=0.44$ ) and inflammation $(I L-6$, rho $=0.54$ ) (all $p<0.01$ ) but by multivariate linear regression analysis only lower SBE and higher adrenaline and IL-6 were independent predictors of higher sVEGFR1. sVEGFR1 also correlated with biomarkers indicative of endothelial glycocalyx degradation (syndecan-1, rho $=0.67$ ), endothelial cell damage $(\mathrm{sTM}$, rho $=0.66)$ and activation $(\mathrm{Ang}-2$, rho $=0.31)$ and hyperfibrinolysis $(\mathrm{tPA}$, rho $=0.39$; D-dimer, rho $=0.58)$ and with activated protein $C($ rho $=0.31)(a l l p<0.01)$. High circulating sVEGFR1 correlated with high early and late transfusion requirements (number of packed red blood cells (RBC) at $1 \mathrm{~h}$ ( $\mathrm{rho}=0.27, \mathrm{p}=$ $0.016), 6 \mathrm{~h}$ ( $\mathrm{rho}=0.27, \mathrm{p}=0.017$ ) and $24 \mathrm{~h}$ ( $\mathrm{ho}=0.31, \mathrm{p}=0.004$ ) but was not associated with mortality.
\end{abstract}

Conclusions: sVEGFR1 increased with increasing injury severity, shock and inflammation early after trauma but only sympathoadrenal activation, hypoperfusion, and inflammation were independent predictors of sVEGFR1 levels. sVEGFR1 correlated strongly with other biomarkers of endothelial activation and damage and with RBC transfusion

\footnotetext{
* Correspondence: sisse.ostrowski@gmail.com

'Section for Transfusion Medicine, Capital Region Blood Bank, Copenhagen University Hospital, Rigshospitalet, Blegdamsvej 9, Copenhagen DK-2100, Denmark

Full list of author information is available at the end of the article
} 
requirements. Sympathoadrenal activation, shock and inflammation may be critical drivers of endothelial activation and damage early after trauma.

Keywords: Trauma, Endothelium, Endothelial cells, Glycocalyx, Soluble vascular growth factor receptor 1, sVEGFR1, sFlt-1, Syndecan-1, Adrenaline, Catecholamines, Sympathoadrenal activation

\section{Introduction}

Critical illness accompanied by shock is associated with endothelial activation and damage, evidenced by high circulating levels of molecules derived from the endothelium such as adhesion and signaling receptors, glycocalyx constituents and Weibel-Palade body contents $[1,2]$. In severely injured patients, high circulating Angiopoietin (Ang)-2 [3], syndecan-1 [4-6], a glycocalyx constituent [7], and soluble thrombomodulin (sTM) $[4,8]$ are indicators of endothelial activation, glycocalyx degradation and endothelial cell damage, respectively; events that contribute directly to trauma pathology by enhancing vascular permeability, hypocoagulability and hyperfibrionlysis in the circulating blood [9-11]. Consequently, high levels of Ang-2, syndecan-1 and sTM all predict a poor outcome in trauma patients $[3,4,6,8]$. Sepsis is another life threatening condition where endothelial disruption, due in part to hyperinflammation and shock, contributes directly to disease pathology [12-14], so high circulating levels of endothelial derived biomarkers also here predict a poor clinical outcome [15]. In a recent study [16], Shapiro and colleagues investigated biomarkers of endothelial activation in 221 adult patients presenting with clinical suspicion of infection, of whom approximately $1 / 3$ developed severe sepsis and $1 / 3$ septic shock. Among several biomarkers, soluble vascular endothelial growth factor (VEGF) receptor 1 (sVEGFR1) (also called soluble fms-like tyrosine kinase 1, sFlt-1) had the strongest association with SOFA score $(\mathrm{r}=0.66, \mathrm{p}<0.001)$ and the highest area under the receiver operator characteristic curve for severe sepsis (0.82) and mortality (0.91) [16].

sVEGFR1 is the truncated soluble form of the membrane bound VEGFR1, which is expressed primarily by endothelial cells and which, together with VEGF, comprise the VEGF-VEGFR system. This system is one of two vascular specific receptor Tyr kinase systems, the second one being the Ang-Tie (Tyr kinase with Ig and EGF homology domains) system [17]. By competing with membrane bound VEGFR1, sVEGFR1 acts as a competitive inhibitor of VEGF signaling in endothelial cells, being a critical regulator of circulating VEGF bioavailability. Thus, sVEGFR1 exerts antiangiogenic, antiinflammatory and vascular stabilizing functions, the latter by interfering with VEGF-induced increases in vascular permeability [18]. Since the circulating level of VEGF is increased in sepsis, it was recently suggested that the early rise in sVEGFR1 in patients whom later develop sepsis, severe sepsis or septic shock, reflects a critical component of the anti-inflammatory host response [16].

Given that endothelial activation and damage are critical hallmarks of both trauma and sepsis pathology [9-14] and that several potential drivers of endothelial disruption are present in both conditions (shock, hyperinflammation, circulating histones $[19,20]$ ), the aim of the present study was to investigate the circulating level and predictive value of sVEGFR1 early after trauma, due to the strong predictive value of this biomarker in sepsis [16]. Also, we investigated potential drivers of sVEGFR1 and sVEGFR1 interrelations with a broad range of endothelial derived biomarkers indicative of endothelial activation, WeibelPalade body release, endothelial cell damage and glycocalyx degradation/shedding, hypothesizing that the level of sVEGFR1 would increase with trauma severity and with the level of sympathoadrenal activation in accordance with previous finding from our group [4].

\section{Materials and methods}

\section{Study design}

Prospective observational cohort study of trauma patients admitted directly to a Level I Trauma Centre (TC) at a tertiary hospital (Rigshospitalet, Copenhagen, Denmark, covering 2.5 million inhabitants) between March 2010 and November 2010. The study is part of an ongoing larger multicentre study, Activation of Coagulation and Inflammation after Trauma 3 (ACIT3) [21], approved by the Regional Ethics Committee (H-4-2009-139), the Danish Data Protection Agency and conducted in accordance with the 2nd Declaration of Helsinki. Written informed consent was obtained from the patients or next of kin. Here we report on findings related to a cohort of 80 patients recruited to the ACIT3 study who had extensive blood samples performed. Data from this cohort have previously been published [22-24].

\section{Patient selection}

ACIT3 study inclusions: Adult trauma patients $(\geq 18$ years) who met criteria for full trauma team activation and had an arterial cannula inserted. The latter was chosen since only patients with expected severe injuries have an arterial cannula placed immediately upon TC admission. Exclusion criteria were arrival in the TC $>2$ hours after injury; > 2,000 $\mathrm{ml}$ of intravenous fluids administered before hospital arrival; transfer from 
another hospital or burns $>5 \%$ total body surface area. Patients were retrospectively excluded if they were taking anticoagulant/antiplatelet medications (except aspirin); had moderate or severe liver disease or had known bleeding diathesis.

The 80 included patients were selected from the first 100 patients recruited to the ACIT3 study with complete data. We intended to include 80 patients because we measured an extensive number of biomarkers by ELISA, with each ELISA kit providing analysis of 80 samples. We aimed at including the most severely injured and/or coagulopathic patients and selected the 80 patients according to: Outcome (mortality or ICU admission post trauma; yes), transfusion of RBC within 6 hours (yes), RTS $(<5.00$, we had not access to ISS before later in the study period) or coagulopathy (APTT $\geq 35 \mathrm{sec}$, INR $\geq 1.2$, Ly30 > 1\%/Cl30 < 95\%; yes). This yielded 70 severely injured/coagulopathic patients, and additionally 10 patients (age 48 years (IQR 43-52), 60\% males) were selected blinded from the remaining 30 patients to match their age and gender (see Table 1 for

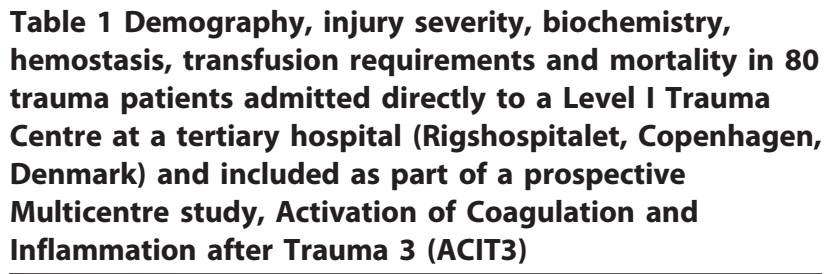

\begin{tabular}{|c|c|c|}
\hline & & Patients \\
\hline $\mathrm{N}$ & & 80 \\
\hline Age & yrs & $46(33-64)$ \\
\hline Gender & male \% & $68 \%(54)$ \\
\hline Blunt trauma & $\%(n)$ & $91 \%(73)$ \\
\hline ISS & score & $17(10-28)$ \\
\hline sTBI & $\%(n)$ & $31 \%(22)$ \\
\hline GCS pre-hospital & score & $13(6-15)$ \\
\hline $\mathrm{pH}$ & & $7.34(7.29-7.39)$ \\
\hline SBE & $\mathrm{mmol} / /$ & $-2.0(-4.0-0.0)$ \\
\hline Lactate & $\mathrm{mmol} / \mathrm{l}$ & $1.7(1.2-2.7)$ \\
\hline $\mathrm{SatO}_{2}$ pre-hospital & $\%$ & $98(93-100)$ \\
\hline Shock index pre-hospital & $\mathrm{HR} / \mathrm{SBP}$ & $0.62(0.50-0.75)$ \\
\hline Hemoglobin & $\mathrm{mmol} / /$ & $8.4(7.3-9)$ \\
\hline Platelet count & $10^{9} / 1$ & $208(173-253)$ \\
\hline $\mathrm{APTT}>35 \mathrm{sec}$ & $\%$ & $8 \%(6)$ \\
\hline INR $>1.2$ & $\%$ & $13 \%(10)$ \\
\hline Saline pre-hospital & $\mathrm{ml}$ & $350(0-1,000)$ \\
\hline MT (> 10 RBCs in $24 \mathrm{~h})$ & $\%(n)$ & $14 \%(11)$ \\
\hline Mortality & $\%(n)$ & $18 \%(14)$ \\
\hline
\end{tabular}

Data are presented as medians (IQR) or $\mathrm{n}$ (\%). ISS, injury severity score; sTBI, severe Traumatic Brain Injury, Abbreviated Injury Score head > 3; PH, prehospital at the site of injury; GCS, Glascow Coma Score scale; RBC, red blood cells; APTT, activated partial thromboplastin time; INR, international normalized ratio; MT, massive transfusion $>10$ red blood cell units the initial 24 hours. details on demography, injury severity etc.). The 20 patients not included in this study, had, compared to the included patients, comparable age and gender $(41$ years (IQR 33-53), 40\% males) and APTT (26 (IQR 2327), NS) but had, as expected, lower ISS (4 (IQR 2-10), $\mathrm{p}<0.001)$, mortality $(0 \%, \mathrm{p}=0.037)$ and INR (1.1 (IQR 1.0-1.1), $\mathrm{p}=0.007)$.

Data on demography, clinical and biochemical parameters, investigations, management and 30-day mortality were recorded and ISS scores were obtained from the Trauma Audit \& Research Network (TARN) database.

No patients received tranexamic acid, adrenaline or noradrenaline prior to blood sampling.

\section{Blood sampling}

Blood was sampled immediately upon arrival for standard arterial blood gas (ABG, Radiometer ABL 725/735, Copenhagen, Denmark), routine biochemistry and research analyses (citrate, heparin, EDTA plasma, serum). Routine biochemistry samples were analyzed in a DS/EN ISO 15189 standardized laboratory by a Sysmex XE-2100 (hemoblobin, platelets, leukocytes) and ACL TOP (APTT, INR, AT, fibrinogen). Plasma samples were ice-cooled immediately whereas serum samples were kept at RT for $1 \mathrm{~h}$ before centrifugation (one (serum) or two (plasma) times $1800 \mathrm{~g}$ at $5^{\circ} \mathrm{C}$ for 10 min) and storage at $-80^{\circ} \mathrm{C}$.

\section{Enzyme linked immunosorbent assay (ELISA) measurements}

sVEGFR1 in addition to soluble biomarkers of sympathoadrenal activation, tissue damage, endothelial cell activation and damage, endothelial glycocalyx degradation/shedding, coagulation activation/inhibition and inflammation were measured in uniplicate by commercially available immunoassays in serum/plasma according to the manufactures recommendations. EDTA plasma: sVEGFR1 (Quantikine, R\&D Systems Europe, Ltd., Abingdon, UK; LLD $3.5 \mathrm{pg} / \mathrm{ml}$ ); adrenaline and noradrenaline (2-CAT ELISA, Labor Diagnostica Nord GmbH \& Co. KG, Nordhorn, Germany; lower limit of detection (LLD) $11 \mathrm{pg} / \mathrm{ml}$ (adrenaline, normal reference $<100 \mathrm{pg} / \mathrm{ml}$ ) and $44 \mathrm{pg} / \mathrm{ml}$ (noradrenaline, normal reference $<600 \mathrm{pg} / \mathrm{ml}$ ), respectively. Histone-complexed DNA fragments (hcDNA, Cell Death Detection ELISAPLUS, Roche, Hvidovre, Denmark; LLD not stated, relative quantification); soluble thrombomodulin (sTM) (Nordic Biosite, Copenhagen, Denmark; LLD 0.38 ng/ $\mathrm{ml}$ ); angiopoietin-2 (Ang-2, R\&D Systems Europe; LLD $8.29 \mathrm{pg} / \mathrm{ml}$ ); D-dimer (ADI; LLD 2-4 ng/ml). Citrate plasma: protein C (PC, Helena Laboratories, Beaumont, TX, US; LLD $5 \%$ of reference plasma); activated protein C (APC, USCNLIFE; LLD $4.2 \mathrm{pg} / \mathrm{ml}$ ); soluble endothelial 
protein $C$ receptor (sEPCR, R\&D Systems Europe; LLD $0.064 \mathrm{ng} / \mathrm{ml}$ ); tissue-type plasminogen activator (tPA, ADI, detects sc-tPA, tc-tPA and tPA/PAI-1 complexes; LLD $1 \mathrm{ng} / \mathrm{ml}$ ); plasminogen activator inhibitor-1 (PAI-1, Assaypro; LLD $0.2 \mathrm{ng} / \mathrm{ml}$ ); prothrombinfragment 1 and 2 (PF1.2, USCNLIFE; LLD $0.043 \mathrm{nmol} / \mathrm{l}$ ); von Willebrand Factor antigen (vWF, Helena Laboratories, LLD 5\% of reference plasma); interleukin-6 (IL-6, Quantikine HS, R\&D Systems Europe; LLD 0.039 pg/ml). Serum: Syndecan-1 (Diaclone SAS, Besancon, France; LLD 2.56 ng/ $\mathrm{ml})$. In each patient, all 16 biomarkers were measured corresponding to a total of $16 * 80=1,280$ measurements, with only 3 missing measurements $(0.2 \%)$.

\section{Statistics}

Statistical analysis was performed using SAS 9.1 (SAS Institute Inc., Cary, NC, US). Correlations were investigated by Spearman correlations and presented by rho and p-values. To investigate the impact of injury severity, shock, tissue damage and inflammation on the sVEGFR1 level, the contribution of ISS, SBE, adrenaline, hcDNA and IL- 6 to the variation in sVEGFR1 was investigated by univariate and multivariate linear regression analysis, presented by regression coefficients $\beta$ with (standard errors), $\mathrm{t}$ - and $\mathrm{p}$-values and $\mathrm{R}^{2}$ for the multivariate model. The association between sVEGFR1 and 30-day mortality was investigated by logistic regression analysis. Data are presented as medians with inter quartile ranges (IQR). P-values $<0.05$ were considered significant.

\section{Results \\ Patients}

The present study included 80 trauma patients with ISS in the entire range (median 17 (IQR 10-28); ISS > $26 \mathrm{n}$ $=23,15-26 \mathrm{n}=26$ and $<15 \mathrm{n}=30$ ), the majority suffering from blunt trauma and approximately one third had severe traumatic brain injury (sTBI, Abbreviated Injury Score head > 3) (Table 1). Most patients (96\%) were referred by mobile emergency care units staffed with anesthetists ( $28 \%$ by helicopter) and blood samples were drawn a median of $68 \mathrm{~min}$ (IQR 48-88) after the injury. Twelve patients (15\%) had increased APTT and/ or INR, $14 \%$ received massive transfusion (> $10 \mathrm{RBC}$ units the initial 24 hours) and overall 30-day mortality was $18 \%$ (Table 1). By thrombelastography (TEG), 11\% had a hypercoagulable TEG (increased clot strength), 1\% a hypocoagulable TEG (reduced clot stregnth) and 1\% had hyperfibrinolysis [22].

\section{sVEGFR1 levels in trauma patients}

In blood sampled on admission from severely injured trauma patients, high circulating soluble VEGF receptor 1 (sVEGFR1) levels correlated with high injury severity
(ISS; rho $=0.46, \mathrm{p}<0.001)$, shock $(\mathrm{SBE} ;$ rho $=-0.38, \mathrm{p}$ $=0.001$ and adrenaline; rho $=0.47, \mathrm{p}<0.001)$, high circulating levels of histones/DAMPs (histone-complexed DNA fragments, rho $=0.44, \mathrm{p}<0.001)$ and inflammation (IL-6; rho $=0.54, \mathrm{p}<0.001$ ) (Table 2 univariate analysis). In the multivariate linear regression analysis, however, only lower SBE and higher adrenaline and IL-6 were independently associated with higher sVEGFR1 (Table 2) suggesting that shock (hypoperfusion, sympathoadrenal activation) and inflammation were critical drivers of high sVEGFR1 levels after trauma. In accordance with this notion, sVEGFR1 also correlated with pre-hospital shock index (pulse rate/systolic blood pressure, rho $=0.28, \mathrm{p}=0.001)$. Furthermore, sVEGFR1 was lower in patients with sTBI as compared to non-sTBI patients (median $146 \mathrm{pg} / \mathrm{ml}$ (IQR 131-202) vs. 220 pg/ $\mathrm{ml}$ (IQR 153-275), $\mathrm{p}=0.011$ ).

\section{sVEGFR1, endothelial disruption and coagulopathy}

sVEGFR1 also correlated positively with biomarkers indicative of endothelial glycocalyx degradation (syndecan-1, Figure 1A), endothelial cell damage (sTM, Figure 1B) and activation (Ang-2 and tPA, Figure 1C-D) whereas it did not correlate with vWF (rho $=-0.12$, NS) or $\mathrm{sEPCR}$ (rho $=-0.02$, NS).

In addition to drivers and biomarkers directly derived from the endothelium, sVEGFR1 also correlated with noradrenaline $($ rho $=0.25, \mathrm{p}=0.026), \mathrm{D}$-dimer $(\mathrm{rho}=$ $0.58, \mathrm{p}<0.001$ ) and activated protein $\mathrm{C}$ (Figure $1 \mathrm{E}$ ) whereas it did not correlate with the non-activated form of protein $\mathrm{C}$ (Figure $1 \mathrm{~F}$ ) or PF1.2 (rho $=0.04, \mathrm{NS}$ ).

sVEGFR1 did not correlate with hemoglobin or platelet count (data not shown), but correlated strongly with leukocyte count (rho $=0.42, \mathrm{p}<0.001$ ) and glucose (rho

Table 2 Univariate and multivariate linear regression analysis of variables associated with SVEGFR1 in trauma patients upon admission to a Level I Trauma Centre

\begin{tabular}{|c|c|c|c|c|c|c|c|}
\hline & \multirow[b]{2}{*}{ Unit } & \multicolumn{3}{|c|}{ Univariate } & \multicolumn{3}{|c|}{ Multivariate $\left(R^{2}=0.38\right)$} \\
\hline & & $\beta$ (SE) & $\begin{array}{c}\text { t- } \\
\text { value }\end{array}$ & $\begin{array}{c}\mathrm{p}- \\
\text { value }\end{array}$ & $\beta$ (SE) & $\begin{array}{c}\text { t- } \\
\text { value }\end{array}$ & $\begin{array}{c}\text { p- } \\
\text { value }\end{array}$ \\
\hline ISS & point & $\begin{array}{c}3.33 \\
(0.95)\end{array}$ & 3.5 & $\begin{array}{c}< \\
0.001\end{array}$ & $\begin{array}{l}-1.38 \\
(1.43)\end{array}$ & -1.0 & 0.340 \\
\hline SBE & $\underset{\mathrm{I}}{\mathrm{mmol} /}$ & $\begin{array}{c}-13.8 \\
(3.3)\end{array}$ & -4.3 & $\begin{array}{c}< \\
0.001\end{array}$ & $-7.9(3.5)$ & -2.3 & 0.027 \\
\hline Adrenaline & $\mathrm{ng} / \mathrm{ml}$ & $\begin{array}{l}34.7 \\
(8.1)\end{array}$ & 4.3 & $\begin{array}{c}< \\
0.001\end{array}$ & $\begin{array}{c}20.1 \\
(10.0)\end{array}$ & 2.0 & 0.048 \\
\hline hcDNA & $\%$ & $\begin{array}{c}1.97 \\
(0.71)\end{array}$ & 2.8 & 0.007 & $\begin{array}{c}0.12 \\
(0.81)\end{array}$ & 0.1 & 0.886 \\
\hline IL-6 & $\mathrm{pg} / \mathrm{ml}$ & $\begin{array}{c}1.13 \\
(0.21)\end{array}$ & 5.4 & $\begin{array}{c}< \\
0.001\end{array}$ & $\begin{array}{c}0.98 \\
(0.29)\end{array}$ & 3.3 & 0.001 \\
\hline
\end{tabular}

Regression coefficients ( $\beta$ ) with standard errors (SE), t- and $p$-values and $\mathrm{R}^{2}$ displayed for the multivariate model. P-values are shown in bold for variables with $\mathrm{p}<0.05$. Predicted change in SVEGFR1 $(\mathrm{pg} / \mathrm{ml})$ associated with one unit increase in injury severity score (ISS), SBE ( $\mathrm{mmol} / \mathrm{l})$, circulating adrenaline (ng/ $\mathrm{ml})$, hcDNA (\%) and IL-6 (pg/ml). 

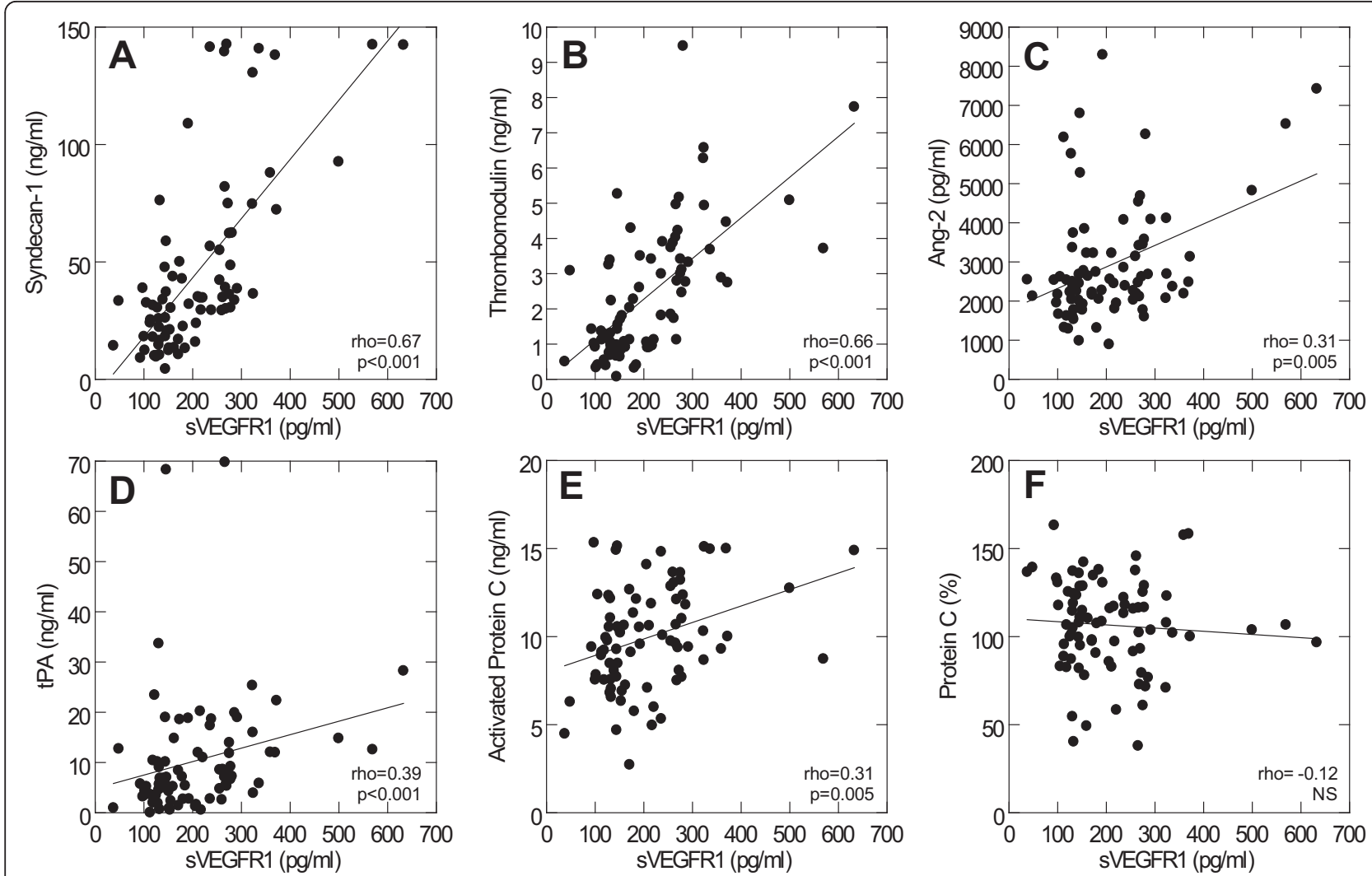

Figure 1 Correlations between sVEGFR1 and biomarkers of endothelial activation and damage and protein C activation on admission in 80 trauma patients. Spearman correlations with rho and p-values are shown for: A) sVEGFR1 (pg/ml) vs. Syndecan-1 (ng/ml), B) sVEGFR1 $(\mathrm{pg} / \mathrm{ml})$ vs. Thrombomodulin $(\mathrm{ng} / \mathrm{ml}), \mathrm{C})$ sVEGFR1 (pg/ml) vs. Ang-2 (pg/ml), D) sVEGFR1 (pg/ml) vs. tPA (ng/ml), E) sVEGFR1 (pg/ml) vs. Activated Protein C (ng/ml) and F) sVEGFR1 (pg/ml) vs. Protein C (\%).

$=0.53, \mathrm{p}<0.001)$, the latter two probably reflecting degree of sympathoadrenal activation. sVEGFR1 did not correlate with APTT, INR, fibrinogen or TEG variables R-time, $\alpha$ angle, maximum amplitude or clot lysis (Ly30, Ly60) (data not shown).

\section{sVEGFR1 and transfusion requirements}

High circulating levels of sVEGFR1 correlated with both early and late transfusion requirements (number of RBC transfusions $1 \mathrm{~h}(\mathrm{rho}=0.27, \mathrm{p}=0.016), 6 \mathrm{~h}(\mathrm{rho}=0.27$, $\mathrm{p}=0.017)$ and $24 \mathrm{~h}(\mathrm{rho}=0.31, \mathrm{p}=0.004)$ after admission). The sVEGFR1 level did not differ between survivors and non-survivors and it did not associate with 30day mortality (data not shown).

\section{Discussion}

In this study, sympathoadrenal activation, hypoperfusion and inflammation were independently associated with high circulating sVEGFR1 levels early after trauma and sVEGFR1 correlated positively with biomarkers indicative of endothelial glycocalyx degradation (syndecan-1), endothelial cell damage (sTM) and Weibel-Palade body degranulation (tPA, Ang-2). High sVEGFR1 levels correlated with high early and late transfusion requirements but did not associate with mortality.

Tissue trauma undoubtedly contributes directly to endothelial injury in trauma, but the concurrent excessive sympathoadrenal activation $[4,25]$, hypoperfusion [8] and inflammation [26] present in shocked trauma patients also induce systemic endothelial activation and damage $[9,10]$. Hypoxia is a potent inducer of endothelial activation [27] and catecholamines also induce active release of procoagulant and profibrinolytic factors from the endothelium $[28,29]$ and in high concentrations, they directly damage the endothelium $[9,30,31]$ in accordance with the recent finding that high circulating adrenaline early after trauma is independently associated with high syndecan-1 levels [25]. In line with this, the present study found that high circulating adrenaline was independently associated with high sVEGFR1, even after adjusting for injury severity, hcDNA, hypoperfusion and inflammation. Though the level of VEGF is reported unchanged and unaffected by injury severity and shock early after trauma [3], the finding here that sVEGFR1 
increased with increasing injury severity, shock and inflammation suggests that the bioavailability of VEGF may change early after trauma. Notably, patients with sTBI had lower circulating sVEGFR1 as compared to non-sTBI trauma patients. The potential (patho)physiologic effects, if any, of these findings however remains to be determined.

In accordance with previous studies reporting of strong interrelations between different endothelial biomarkers in trauma [3] and sepsis [16], sVEGFR1 correlated with other endothelial derived biomarkers in this study. Importantly, sVEGFR1 was strongly positively correlated with both syndecan-1 and sTM, biomarkers of endothelial glycocalyx degradation/shedding and endothelial cell damage, respectively, and both carrying prognostic value in trauma patients $[4,6,8]$. Also, sVEGFR1 correlated with Ang-2 and tPA, which are both Weibel-Palade constituents [29] and inducers of fibrinolysis and enhanced vascular permeability, and with activated protein $C$, a potent natural anticoagulant and inducer of fibrinolysis. Considering Ang-2, this is increased early after trauma and associated with poor clinical outcome [3]. Ang-2 is expressed almost exclusively by endothelial cells and is induced dramatically and released instantaneously from Weibel-Palade bodies upon endothelial activation $[17,29,32]$ and its release results in rapid (autocrine) destabilization of the endothelium which, through endothelial activation and increased vascular permeability, triggers an inflammatory response $[17,32]$.

Despite the interrelation between sVEGFR1 and other endothelial activation and damage biomarkers in accordance with the finding in sepsis by Shapiro et al [16], sVEGFR1 did not associate with mortality as observed in sepsis. Whether this is due to a type II error due to the low number of subjects investigated in the present study or reflects biologic differences between the trauma and sepsis populations remains to be determined.

Given the finding that sVEGFR1 correlated with transfusion requirements, it should be emphasized that all biochemistry variables and biomarkers were measured in arrival blood samples taken before administration of any blood products and hence sampled before any potential introduction of bias (e.g., content of sVEGFR1 in blood products). Though sVEGFR1 correlated with transfusion requirements, it did not correlate with any TEG variables.

It may seem counterintuitive that active release of endothelial derived molecules in the most severely injured and potentially bleeding trauma patients promotes progressive hypocoagulability in the circulating blood [4,10,11,25,33-36] through induction of endogenous anticoagulation (activated protein C, sTM), hyperfibrinolysis (tPA, activated protein $C$ ) $[8,11]$ and heparinization (glycocalyx shedding) $[4,9,37]$. We recently hypothesized that this progressive hypocoagulability, from a systems biology perspective, reflects an evolutionary adapted response that counterbalances the progressively more damaged and procoagulant endothelium in order to keep the microcirculation open [9]. Furthermore, several of the endothelial derived molecules that promote hypocoagulability exert potent antiinflammatory and cytoprotective functions [13,38-40] that may ultimately generate at survival advantage in injured individuals [41]. In addition to progressive hypocoagulability, severe trauma is associated with increased vascular permeability which, in part, may result from downstream effects of glycocalyx degradation $[42,43]$ and Ang-2 release [17,32]. In a context without resuscitation (from an evolutionary perspective) the increase in vascular permeability may generate a survival advantage since the rapid shift of volume from the intra- to the extra-vascular compartment in a bleeding subject may both lower blood pressure and contain fluid within the body for latter mobilization if the subject survives, which seems favorable as compared to bleeding out a large un-replaceable intravascular volume. Such response (or a more exaggerated one) may, however, not generate the same survival benefit in a context with aggressive volume resuscitation and life support in severely injured individuals and this may explain the consistent finding that the highest levels of several endothelial derived molecules are negatively associated with outcome in trauma $[3-6,8]$.

The results presented here are subject to the limitations inherent to observational studies and, thereby, do not allow independent evaluation of the cause-and-effect relationship suggested. Furthermore, the low number of subjects, and especially the low number of severely injured patients, included in the present study increases the risk of introducing a type II error and the multiple testing increases the risk of a type I error, emphasizing that the reported findings should be confirmed in a larger cohort of patients.

\section{Conclusions}

The present study demonstrated that the level of sVEGFR1 early after trauma increased with increasing injury severity, sympathoadrenal activation, hypoperfusion and inflammation. Furthermore, we found strong interrelations between sVEGFR1 and circulating levels of other endothelial derived biomarkers. In severely injured patients, endothelial activation and disruption promote progressive hypocoagulability and enhanced vascular permeability and may increase the systemic level of soluble antiinflammatory and cytoprotective mediators, events that may contribute to reduce bleeding and maintain blood flow in the microcirculation and 
thereby from an evolutionary perspective generate a survival advantage.

\begin{abstract}
Abbreviations
ACIT: Activation of coagulation and inflammation after trauma; Ang: Angiopoietin; Ang-2: Angiopoietin-2; APC: Activated protein C; APTT: Activated partial thromboplastin time; ELISA: Enzyme linked immunosorbent assay; GCS: Glasgow Coma Score scale; hcDNA: Histone-complexed DNA fragments; ICU: Intensive care unit; ISS: Injury Severity Score; IL-6: Interleukin6; INR: International normalized ratio; IQR: Inter quartile range; MT: Massive transfusion; PAl-1: Plasminogen activator inhibitor-1; PC: Protein C; PF1.2: Prothrombinfragment 1; RBC: Red blood cells; $\mathrm{SatO}_{2}$ : Arterial oxygen saturation; SBE: Standard base excess; SEPCR: Soluble endothelial protein C receptor; sflt-1: Soluble fms-like tyrosine kinase 1; SOFA score: The Sequential Organ Failure Assessment score; sTM: Soluble thrombomodulin; sVEGFR1: Soluble vascular endothelial growth factor receptor 1; TARN Trauma audit \& research network; TC: Trauma centre; tPA: Tissue-type plasminogen activator; VEGF: Vascular endothelial growth factor; VWF: Von Willebrand Factor antigen.
\end{abstract}

\section{Acknowledgements}

Karen Dyeremose and Marie Helena Andersson are thanked for the skilled technical assistance.

The Danish Council for Independent Research (Medical Sciences), Aase and Ejnar Danielsens Foundation, L. F. Foghts Foundation, A. P. Møller and wife Chastine Mc-Kinney Møllers Foundation (Medical Sciences).

\section{Author details}

'Section for Transfusion Medicine, Capital Region Blood Bank, Copenhagen University Hospital, Rigshospitalet, Blegdamsvej 9, Copenhagen DK-2100, Denmark. ${ }^{2}$ Department of Anesthesia, Copenhagen University Hospital, Rigshospitalet, Blegdamsvej 9, Copenhagen DK-2100, Denmark. ${ }^{3}$ The Trauma Centre, Centre of Head and Orthopedics, Copenhagen University Hospital, Rigshospitalet, Blegdamsvej 9, Copenhagen DK-2100, Denmark. ${ }^{4}$ Department of Intensive Care, Copenhagen University Hospital, Rigshospitalet, Blegdamsvej 9, Copenhagen DK-2100, Denmark. ${ }^{5}$ Department of Neurointensive Care, Copenhagen University Hospital, Rigshospitalet, Blegdamsvej 9, Copenhagen DK-2100, Denmark. ${ }^{6}$ Department of Cardiothoracic Anesthesia, Copenhagen University Hospital, Rigshospitalet, Blegdamsvej 9, Copenhagen DK-2100, Denmark.

\section{Authors' contributions}

SRO contributed to the design of the study, analysis and interpretation of data, figure drafting and drafting/writing/revising of the manuscript. AMS and CFL contributed to the design of the study and revised the manuscript critically. NAW, AP, KLW and MW contributed to the acquisition and interpretation of data and revised the manuscript critically. PIJ contributed to the conception and design of the study, interpretation of data and drafting/ writing/revising of the manuscript. All authors read and approved the final manuscript.

\section{Competing interests}

The authors declare that they have no competing interests.

Received: 7 December 2011 Accepted: 10 April 2012 Published: 10 April 2012

\section{References}

1. Aird WC: Endothelium as an organ system. Crit Care Med 2004, 32 S271-S279.

2. Aird WC: Spatial and temporal dynamics of the endothelium. J Thromb Haemost 2005, 3:1392-1406.

3. Ganter MT, Cohen MJ, Brohi K, Chesebro BB, Staudenmayer KL, Rahn P, Christiaans SC, Bir ND, Pittet JF: Angiopoietin-2, marker and mediator of endothelial activation with prognostic significance early after trauma? Ann Surg 2008, 247:320-326.

4. Johansson PI, Stensballe J, Rasmussen LS, Ostrowski SR: A high admission syndecan-1 level, a marker of endothelial glycocalyx degradation, is associated with inflammation, protein c depletion, fibrinolysis, and increased mortality in trauma patients. Ann Surg 2011, 254:194-200.

5. Haywood-Watson R, Pati S, Kozar R, Faz J, Holcomb JB, Gonzalez E: Human Micro-Vascular Barrier Disruption after Hemorrhagic Shock. J Surg Res 2010, 158:313, (Abstract 37.4).

6. Haywood-Watson RJ, Holcomb JB, Gonzalez EA, Peng Z, Pati S, Park PW, Wang W, Zaske AM, Menge T, Kozar RA: Modulation of syndecan-1 shedding after hemorrhagic shock and resuscitation. PLoS One 2011, 6: e23530.

7. Rehm M, Bruegger D, Christ F, Conzen $\mathrm{P}$, Thiel M, Jacob M, Chappell $\mathrm{D}$, Stoeckelhuber M, Welsch U, Reichart B, Peter K, Becker BF: Shedding of the endothelial glycocalyx in patients undergoing major vascular surgery with global and regional ischemia. Circulation 2007, 116:1896-1906.

8. Brohi K, Cohen MJ, Ganter MT, Matthay MA, Mackersie RC, Pittet JF: Acute traumatic coagulopathy: initiated by hypoperfusion: modulated through the protein C pathway? Ann Surg 2007, 245:812-818.

9. Johansson Pl, Ostrowski SR: Acute coagulopathy of trauma: balancing progressive catecholamine induced endothelial activation and damage by fluid phase anticoagulation. Med Hypotheses 2010, 75:564-567.

10. Hess JR, Brohi K, Dutton RP, Hauser CJ, Holcomb JB, Kluger Y, MackwayJones K, Parr MJ, Rizoli SB, Yukioka T, Hoyt DB, Bouillon B: The coagulopathy of trauma: a review of mechanisms. J Trauma 2008, 65:748-754.

11. Frith $D$, Brohi $K$ : The acute coagulopathy of trauma shock: clinical relevance. Surgeon 2010, 8:159-163.

12. Marshall JC: Inflammation, coagulopathy, and the pathogenesis of multiple organ dysfunction syndrome. Crit Care Med 2001, 29:S99-S106.

13. Levi M, van der Poll T: Inflammation and coagulation. Crit Care Med 2010, 38:S26-S34.

14. Aird WC: The role of the endothelium in severe sepsis and multiple organ dysfunction syndrome. Blood 2003, 101:3765-3777.

15. Pierrakos C, Vincent JL: Sepsis biomarkers: a review. Crit Care 2010, 14:R15.

16. Shapiro NI, Schuetz P, Yano K, Sorasaki M, Parikh SM, Jones AE, Trzeciak S, Ngo L, Aird WC: The association of endothelial cell signaling, severity of illness, and organ dysfunction in sepsis. Crit Care 2010, 14:R182.

17. Augustin $H G$, Koh GY, Thurston $G$, Alitalo K: Control of vascular morphogenesis and homeostasis through the angiopoietin-Tie system. Nat Rev Mol Cell Biol 2009, 10:165-177.

18. Wu FT, Stefanini MO, Mac GF, Kontos CD, Annex BH, Popel AS: A systems biology perspective on SVEGFR1: its biological function, pathogenic role and therapeutic use. J Cell Mol Med 2010, 14:528-552.

19. Zhang $Q$, Raoof $M$, Chen $Y$, Sumi $Y$, Sursal T, Junger W, Brohi K, Itagaki K, Hauser CJ: Circulating mitochondrial DAMPs cause inflammatory responses to injury. Nature 2010, 464:104-107.

20. Xu J, Zhang X, Pelayo R, Monestier M, Ammollo CT, Semeraro F, Taylor FB, Esmon NL, Lupu F, Esmon CT: Extracellular histones are major mediators of death in sepsis. Nat Med 2009, 15:1318-1321.

21. Davenport R, Curry N, Manson J, De'ath H, Coates A, Rourke C, Pearse R, Stanworth S, Brohi K: Hemostatic effects of fresh frozen plasma may be maximal at red cell ratios of 1:2. J Trauma 2011, 70:90-96.

22. Ostrowski SR, Sorensen AM, Larsen CF, Johansson PI: Thrombelastography and biomarker profiles in acute coagulopathy of trauma: a prospective study. Scand I Trauma Resusc Emerg Med 2011, 19:64.

23. Johansson PI, Sørensen AM, Perner A, Welling KL, Wanscher M, Larsen CF, Ostrowski SR: Disseminated intravascular coagulation or acute coagulopathy of trauma shock early after trauma? An observational study. Crit Care 2011, 15:R272.

24. Johansson PI, Sørensen AM, Perner A, Welling KL, Wanscher M, Larsen CF, Ostrowski SR: Elderly trauma patients have high circulating noradrenaline levels but attenuated release of adrenaline, platelets and leukocytes in response to increasing injury severity. Crit Care Med 2011.

25. Johansson PI, Stensballe J, Rasmussen LS, Ostrowski SR: High circulating adrenaline levels at admission predict increased mortality after trauma. $J$ Trauma 2012, 72:428-436.

26. Ganter MT, Brohi K, Cohen MJ, Shaffer LA, Walsh MC, Stahl GL, Pittet JF: Role of the alternative pathway in the early complement activation following major trauma. Shock 2007, 28:29-34.

27. Ten VS, Pinsky DJ: Endothelial response to hypoxia: physiologic adaptation and pathologic dysfunction. Curr Opin Crit Care 2002 8:242-250. 
28. von Kanel R, Dimsdale JE: Effects of sympathetic activation by adrenergic infusions on hemostasis in vivo. Eur J Haematol 2000, 65:357-369.

29. Lowenstein CJ, Morrell CN, Yamakuchi M: Regulation of Weibel-Palade body exocytosis. Trends Cardiovasc Med 2005, 15:302-308.

30. Makhmudov RM, Mamedov Y, Dolgov W, Repin VS: Catecholaminemediated injury to endothelium in rabbit perfused aorta: a quantitative analysis by scanning electron microscopy. Cor Vasa 1985, 27:456-463.

31. Kristova V, Kriska M, Canova R, Hejdova E, Kobzova D, Dobrocky P: Endothelial changes following repeated effect of vasoconstrictive substances in vitro. Acta Physiol Hung 1993, 81:363-370.

32. Fiedler $\mathrm{U}$, Augustin $\mathrm{HG}$ : Angiopoietins: a link between angiogenesis and inflammation. Trends Immunol 2006, 27:552-558.

33. Johansson PI, Stissing T, Bochsen L, Ostrowski SR: Thrombelastography and tromboelastometry in assessing coagulopathy in trauma. Scand J Trauma Resusc Emerg Med 2009, 17:45.

34. Bluth MH, Kashuk JL: Mechanistic links in trauma-induced coagulopathy: a tale of two cities. Ann Surg 2011, 254:20-21.

35. Gando S, Sawamura A, Hayakawa M: Trauma, shock, and disseminated intravascular coagulation: lessons from the classical literature. Ann Surg 2011, 254:10-19.

36. Holcomb JB: A novel and potentially unifying mechanism for shock induced early coagulopathy. Ann Surg 2011, 254:201-202.

37. Senzolo M, Coppell J, Cholongitas E, Riddell A, Triantos CK, Perry D, Burroughs AK: The effects of glycosaminoglycans on coagulation: a thromboelastographic study. Blood Coagul Fibrinolysis 2007, 18:227-236.

38. Mosnier LO, Zlokovic BV, Griffin JH: The cytoprotective protein C pathway. Blood 2007, 109:3161-3172.

39. Kim YH, Park JH, Hong SH, Koh JY: Nonproteolytic neuroprotection by human recombinant tissue plasminogen activator. Science 1999, 284:647-650

40. Fitzgerald ML, Wang Z, Park PW, Murphy G, Bernfield M: Shedding of syndecan-1 and -4 ectodomains is regulated by multiple signaling pathways and mediated by a TIMP-3-sensitive metalloproteinase. J Cell Biol 2000, 148:811-824.

41. Chesebro BB, Rahn P, Carles M, Esmon CT, Xu J, Brohi K, Frith D, Pittet JF, Cohen MJ: Increase in activated protein $C$ mediates acute traumatic coagulopathy in mice. Shock 2009, 32:659-695.

42. Becker BF, Chappell D, Bruegger D, Annecke T, Jacob M: Therapeutic strategies targeting the endothelial glycocalyx: acute deficits, but great potential. Cardiovasc Res 2010, 87:300-310.

43. Reitsma S, Slaaf DW, Vink H, van Zandvoort MA, oude Egbrink MG: The endothelial glycocalyx: composition, functions, and visualization. Pflugers Arch 2007, 454:345-359.

doi:10.1186/1757-7241-20-27

Cite this article as: Ostrowski et al:: High levels of soluble VEGF receptor 1 early after trauma are associated with shock, sympathoadrenal activation, glycocalyx degradation and inflammation in severely injured patients: a prospective study. Scandinavian Journal of Trauma

Resuscitation and Emergency Medicine 2012 20:27.

\section{Submit your next manuscript to BioMed Central and take full advantage of:}

- Convenient online submission

- Thorough peer review

- No space constraints or color figure charges

- Immediate publication on acceptance

- Inclusion in PubMed, CAS, Scopus and Google Scholar

- Research which is freely available for redistribution

Submit your manuscript at www.biomedcentral.com/submit
Ciomed Central 